\title{
Body Mass Index, Eating Habits and Physical Activity Among Dietetics Students in Universiti Sultan Zainal Abidin
}

\author{
${ }^{1}$ Nurul Syahirah Rusli, ${ }^{*}$ Sakinah Harith \\ ${ }^{1}$ Faculty of Health Sciences, Universiti Sultan Zainal Abidin (UniSZA), Kuala Nerus, Terengganu, Malaysia \\ *Corresponding author: Sakinah Harith, e-mail: sakinahharith@unisza.edu.my
}

\begin{abstract}
University life is a critical period of change in eating habits. Weight gain is a serious problem among youths who are experiencing a change in university life. Universities are potentially important settings for promotion of healthy diet and weight management practice for healthy future. Present study aimed to assess physical activity, eating habits and their association with body mass index (BMI) in dietetics students at Universiti Sultan Zainal Abidin (UniSZA). A total of 126 students were involved in answering a set of survey questions as well as weight and height measurements. Data were analyzed using SPSS version 22.0. Result showed that, $9.5 \%$ of dietetics students were obese and $25.4 \%$ were overweight. Breakfast was the most frequently skipped meal (71.4\%) with the main reason of time management followed by busyness in attending lectures and doing readings. Majority of students (73\%) will take a snack when they skipped their meal time. Most of the students consume fruits sometimes $(55.6 \%)$ and $37.3 \%$ of them also consume vegetables sometimes. Most of the students (37.3\%) consumes fast food one to three times per month. More than half of the students (59.5\%) prefer to eat with friends. Majority of students have moderate physical activity $(42.9 \%)$. However, this study also did not show association between physical activity, eating habits and BMI. In a nutshell, health programs are necessary to create awareness of nutrition and a healthy lifestyle among youth as the arising of obesity incidence among youth is worrying.
\end{abstract}

\section{ARTICLE INFORMATION}

\author{
Submitted: 09/11/2020 \\ Revised: $18 / 11 / 2020$ \\ Accepted: $28 / 11 / 2020$ \\ Published Online: 30/11/2020
}

Keywords:
Body Mass Index
Eating habits
Physical activity
University students

How to cite this article: Rusli, N. S., Harith, S. (2020). Body Mass Index, Eating Habits and Physical Activity Among Dietetics Students in Universiti Sultan Zainal Abidin. JNS : Journal of Nutrition Science, 1(2), 1-12.

\section{Introduction}

Overweight and obesity continue to increase progressively worldwide, affecting all ages, sexes and races. There is powerful evidence that increase in the energy density of the diet by fat or sugar, together with contribution from eating behaviors like snacking and eating out, promote unhealthy weight gain through passive overconsumption of energy (WHO,2003). Lack of physical activity also can cause accumulation of body fat and lead to weight gain (Shah et al., 2014).

Obesity is caused by an excessive body fat that has accumulated in the body and can cause an adverse effect on health (Majeed, 2015). It is obvious that what a person eats has a serious effect on his/her health. Maintaining a healthy weight is a crucial way to make sure that the person will stay in good health and decrease the possibilities of acquired a number of long terms health problems (Mahfouz et al., 2016). One of the major public health concerns among young adults who are experiencing transition into university life is poor eating habits and weight gain (Nelson et al, 2008).

Several studies have shown that university tend to have poor eating habits (Gan et al, 2011). Previous studies reported that university students have inappropriate eating habits such as skipping meals, taking high-energy intake with high fat and 
sodium but low calcium and iron (Abdul et al., 2015). They typically enter a dynamic transitional period of new independence from their parents that is characterized by rapid, interrelated changes in body, mind, and social relationships (Pullman et al., 2009) and experience a new environment that generally involves increased workload and stress, altered patterns of life, which are significant contributors to unhealthy lifestyles.

Previous studies (Irwin, 2007) on healthy lifestyles indicate that majority of university students are minimally engaged in health-promoting behaviors and exhibit behavioral health risks, such as tobacco use (Jamaluddin et al., 2015), alcohol and substance abuse, and improper diet and physical activities (Laska et al., 2009).

As a result, this young adult failed to meet dietary requirement for most of macronutrient and micronutrient. Previous studies have showed that unhealthy lifestyle after becoming a university student, including smoking and alcohol consumption, and poor food preferences may be associated to moving away from home, poor cooking skills, low income, and little time availability to engage with physical activity recreation (Gustavo de Souza et al, 2014). This type of lifestyle changes can lead to weight gain and an increase in body fat composition during the years of the university education (Esra Gunes et al., 2012).

In Malaysia, the prevalence of obesity among Malaysians aged 15 years and older was reported to be $11.7 \%$ in a national study (Rampal et al., 2007). Therefore, the aim of this study was to assess the physical activity, eating habits and BMI among dietetics students in UniSZA, a public university in Malaysia

\section{Method}

\section{Participants and ethical consideration}

A cross-sectional study was conducted at Universiti Sultan Zainal Abidin (UniSZA), in Malaysia. For the purpose of this study, all dietetics undergraduate students were included in the study. However, we exclude Year 4 students as they are currently undergoes their clinical placement and does not available in the campus. Therefore, the final sample size of the students was 113 dietetics undergraduate students. A written consent was obtained those agreed to participate in the study. Ethical approval for the study was granted by the Human Research Ethics Committee of Universiti Sultan Zainal Abidin (UniSZA/UHREC/2019/146)

\section{Socio-demographic and anthropometric measurements}

Socio-demographic information's including; Age, gender, date of birth, marital status, the source of income, living arrangement, the field of study and place of living were self-reported. Body weight was measured using a Seca Digital Scale (813, Hamburg, Germany) to the nearest $0.1 \mathrm{~kg}$. Participants were asked to remove their shoes and step on the scale. Height was measured using Seca stadiometer (217, Hamburg, Germany), the participants stood straight with their back facing the body meter, and the measuring beam is pulled down to rest on the head, and it was recorded to the nearest $0.1 \mathrm{~cm}$. BMI was calculated, and was used to categorize the weight status of the participants as underweight (BMI less than $18.5 \mathrm{~kg} / \mathrm{m}^{2}$ ), normal (BMI $=18.5$ to $23 \mathrm{~kg} / \mathrm{m}^{2}$ ), overweight (BMI 23 to $27.5 \mathrm{~kg} / \mathrm{m}^{2}$ ) and obese (BMI greater or equals to $\left.27.5 \mathrm{~kg} / \mathrm{m}^{2}\right)$ (WHO 2004).

\section{Eating Behaviors Questionnaire}

Eating Behavior Questionnaire (EBQ) was used to determine the eating behavior of the subjects. EBQ is a nine-item scale that assesses the frequency of meal consumption, the frequency of snacking between meals, types of snacks consumed, and frequency of eating outside the home and take away foods, use of dietary supplements, dietary practice and participation in weight management programs (Chin \& Mohd Nasir, 2009). It 
Table 1 Socio-demographic characteristics and its association with BMI

\begin{tabular}{|c|c|c|c|c|c|c|c|}
\hline \multicolumn{2}{|c|}{ Q: Questions } & UW & NW & OW & OB & Total $(\mathrm{n} / \%)$ & $p$-value \\
\hline 1) & Gender & & & & & & \\
\hline & a. Male & $0(0.0)$ & $4(3.2)$ & $1(0.8)$ & $2(1.6)$ & $7(5.6)$ & 0.694 \\
\hline & b. Female & 14(11.1) & $64(50.8)$ & $31(24.6)$ & $10(7.9)$ & $119(94.4)$ & \\
\hline 2) & What is your source of income? & & & & & & \\
\hline & a. Scholarship & $1(0.8)$ & $11(8.7)$ & $3(2.4)$ & $1(0.8)$ & $16(12.7)$ & 0.373 \\
\hline & b. Scholarship and family & $12(9.5)$ & $57(45.2)$ & $28(22.2)$ & $10(7.9)$ & $107(84.9)$ & \\
\hline & c. Scholarship and self & $1(0.8)$ & $0(0.0)$ & $1(0.8)$ & $1(0.8)$ & $3(2.4)$ & \\
\hline 3) & Where do you live? & & & & & & \\
\hline & a. On campus & $5(4.0)$ & $40(31.7)$ & $12(9.5)$ & $7(5.6)$ & $64(50.8)$ & 0.211 \\
\hline & b. Off campus & $9(7.1)$ & $28(22.2)$ & $20(15.9)$ & $5(4.0)$ & $62(49.2)$ & \\
\hline 4) & Living arrangement & & & & & & \\
\hline & a. Alone & $1(0.8)$ & $6(4.8)$ & $0(0.0)$ & $0(0.0)$ & $7(5.6)$ & 0.769 \\
\hline & b. With roommates & $12(9.5)$ & $60(47.6)$ & $30(23.8)$ & $10(7.9)$ & $112(88.9)$ & \\
\hline & c. With family & $1(0.8)$ & $2(1.6)$ & $2(1.6)$ & $2(1.6)$ & $7(5.6)$ & \\
\hline
\end{tabular}

Pearson Chi-square analysis ( $2 \times 2$ table), $p$-value less than 0.05 is considered significant.

*significantly at $p<0.05$

was scaled 1 to 6 ( $1=$ every day, $2=4$ to 6 days a week, $3=2$ to 3 days a week, $4=$ once in a week, $5=1$ to 3 times a month, and $6=$ never or less than once a month).

\section{Data Analysis}

Statistical analysis was conducted using a statistical program for science (IBM SPSS, Version 20.0). Descriptive statistic was carried out, and the result is presented as frequencies and percentages for categorical variables and as means and standard deviations for continuous variables. The association between BMI, sociodemographic data, physical activity and eating habits was determined using the Chi- square test. Significant level was set at $p<0.005$.

\section{Results}

Socio-demography characteristics of the participants and its association with BMI

Table 1 presents the socio-demographic characteristics of the students in the present study. Of 126 students, seven are male and 119 are female with most of the participants were single (99.2\%). Most of the participant's income is from scholarship and family $(84.9 \%)$. Half of the participants reside in the campus $(50.8 \%)$ and the other half reside off campus. $88.9 \%$ of the participants lived with their roommates and the remaining lived alone $(5.6 \%)$ or with their family (5.6\%). There are no significant association between sociodemographic characteristics and BMI $(P>0.05)$.

\section{Anthropometric measurement}

In Table 2, the mean body weight and height of the participants were $54.7 \mathrm{~kg}$ and $156.0 \mathrm{~cm}$ respectively. The mean BMI of the participants is $22.4 \mathrm{~kg} / \mathrm{m} 2$ which is normal range. Majority of the participants had normal weight (54.0\%) and $34.9 \%$ of the participants were overweight and obese. Only $11.1 \%$ of the participants are underweight.

Table 2 Body Mass Index (BMI)categories of the participants

\begin{tabular}{lcc}
\hline Classification & $\begin{array}{c}\text { Total } \\
(\mathrm{n} / \%)\end{array}$ & Mean \pm SD (BMI) \\
\hline Underweight & $14(11.1)$ & $17.4 \pm 0.7903$ \\
\hline Normal & $68(54.0)$ & $20.9 \pm 1.3980$ \\
\hline Overweight & $32(25.4)$ & $25.5 \pm 1.0815$ \\
\hline Obese & $12(9.5)$ & $30.7 \pm 1.6475$ \\
\hline Weight $\mathbf{( k g )}$ & Mean \pm SD \\
\hline Height $\mathbf{( c m )}$ & $54.7 \pm 10.5566$ \\
\hline BMI $\mathbf{( k g / \mathbf { m } ^ { 2 } )}$ & $156.0 \pm 5.4291$ \\
\hline
\end{tabular}

\section{Eating behavior of the students}

Meal and snack consumption and its association with BMI.

In Table $3,27 \%$ of the participants consume breakfast, $61.1 \%$ of the participants consume lunch and $45.2 \%$ of the participants consume dinner daily. 
Available at http://jurnal.utu.ac.id/JNS/article/view/2757

Table 3 Meal and snacks consumption of the participants and its association with BMI Questions UW NW OW

$\mathrm{OB}$
Total $(\mathrm{n} / \%) \quad p$-value

1) How frequent do you consume breakfast?
a. Everyday
b. 4 to 6 days per week
c. 2 to 3 days per week
d. Once a month
e. 1 to 3 times per month
f. Never

$\begin{array}{lc}2(1.6) & 20(15.9) \\ 6(4.8) & 23(18.3) \\ 4(3.2) & 20(15.9) \\ 2(1.6) & 1(0.8) \\ 0(0.0) & 3(2.4) \\ 0(0.0) & 1(0.8)\end{array}$

$9(7.1)$

$3(2.4)$

$34(27.0)$

0.374

$9(7.1) \quad 5(4.0) \quad 43(34.1)$

$9(7.1) \quad 3(2.4) \quad 36(28.6)$

$1(0.8) \quad 0(0.0) \quad 4(3.2)$

$4(3.2) \quad 1(0.8) \quad 8(6.3)$

2) How frequent do you consume morning tea?

$\begin{array}{ll}\text { a. } & \text { Everyday } \\ \text { b. } & 4 \text { to } 6 \text { days per week } \\ \text { c. } & 2 \text { to } 3 \text { days per week } \\ \text { d. } & \text { Once a month } \\ \text { e. } & 1 \text { to } 3 \text { times per month } \\ \text { f. } & \text { Never }\end{array}$

3) How frequent do you consume lunch?
a. Everyday
b. $\quad 4$ to 6 days per week
c. $\quad 2$ to 3 days per week
d. Once a month
e. 1 to 3 times per month
f. Never

4) How frequent do you consume afternoon tea?

\begin{tabular}{|c|c|c|c|c|c|c|}
\hline a. & Everyday & $1(0.8)$ & $3(2.4)$ & $1(0.8)$ & $0(0.0)$ & $5(4.0)$ \\
\hline b. & 4 to 6 days per week & $2(1.6)$ & $3(2.4)$ & $1(0.8)$ & $0(0.0)$ & $6(4.8)$ \\
\hline c. & 2 to 3 days per week & $7(5.6)$ & $21(16.7)$ & $10(7.9)$ & $4(3.2)$ & $42(33.3)$ \\
\hline d. & Once a month & $0(0.0)$ & $10(7.9)$ & $4(3.2)$ & $2(1.6)$ & $16(12.7)$ \\
\hline e. & 1 to 3 times per month & $2(1.6)$ & $14(11.1)$ & $5(4.0)$ & $3(2.4)$ & $24(19.0)$ \\
\hline$f$. & Never & $2(1.6)$ & $17(13.5)$ & $11(8.7)$ & $3(2.4)$ & $33(26.2)$ \\
\hline
\end{tabular}

5) How frequent do you consume dinner?

$\begin{array}{cccccc}1(0.8) & 4(3.2) & 1(0.8) & 1(0.8) & 7(5.6) & 0.398 \\ 1(0.8) & 7(5.6) & 3(2.4) & 2(1.6) & 13(10.3) & \\ 7(5.6) & 20(15.9) & 8(6.3) & 3(2.4) & 38(30.2) & \end{array}$

$\begin{array}{lllll}1(0.8) & 8(6.3) & 5(4.0) & 2(1.6) & 16(12.7)\end{array}$

$\begin{array}{lllll}1(0.8) & 10(7.9) & 7(5.6) & 3(2.4) & 19(15.1)\end{array}$

$\begin{array}{lllll}3(2.4) & 19(15.1) & 8(6.3) & 1(0.8) & 33(26.2)\end{array}$

\begin{tabular}{|c|c|c|c|c|c|c|c|}
\hline a. & Everyday & $8(6.3)$ & $32(25.4)$ & $10(7.9)$ & $7(5.6)$ & $57(45.2)$ & $* 0.007$ \\
\hline b. & 4 to 6 days per week & $3(2.4)$ & $17(13.5)$ & $10(7.9)$ & $3(2.4)$ & $33(26.2)$ & \\
\hline c. & 2 to 3 days per week & $0(0.0)$ & $12(9.5)$ & $0(0.0)$ & $0(0.0)$ & $12(9.5)$ & \\
\hline d. & Once a month & $1(0.8)$ & $4(3.2)$ & $2(1.6)$ & $1(0.8)$ & $8(6.3)$ & \\
\hline e. & 1 to 3 times per month & $2(1.6)$ & $2(1.6)$ & $10(7.9)$ & $1(0.8)$ & $15(11.9)$ & \\
\hline f. & Never & $0(0.0)$ & $1(0.8)$ & $0(0.0)$ & $0(0.0)$ & $1(0.8)$ & \\
\hline \multicolumn{8}{|c|}{ How frequent do you consume supper? } \\
\hline a. & Everyday & $2(1.6)$ & $3(2.4)$ & $0(0.0)$ & $0(0.0)$ & $5(4.0)$ & $* 0.017$ \\
\hline b. & 4 to 6 days per week & $1(0.8)$ & $6(4.8)$ & $2(1.6)$ & $0(0.0)$ & $9(7.1)$ & \\
\hline c. & 2 to 3 days per week & $9(7.1)$ & $29(23.0)$ & $10(7.9)$ & $5(4.0)$ & $53(42.1)$ & \\
\hline d. & Once a month & $0(0.0)$ & $8(6.3)$ & $6(4.8)$ & $2(1.6)$ & $16(12.7)$ & \\
\hline e. & 1 to 3 times per month & $1(0.8)$ & $14(11.1)$ & $8(6.3)$ & $1(0.8)$ & $24(19.0)$ & \\
\hline f. & Never & $1(0.8)$ & $8(6.3)$ & $6(4.8)$ & $4(3.2)$ & $19(15.1)$ & \\
\hline
\end{tabular}

Pearson Chi-square analysis ( $2 \times 2$ table), $p$-value less than 0.05 is considered significant.

*significantly at $p<0.05$

Daily consumption of snack during morning tea was higher in the morning $(5.6 \%)$ compare to during afternoon tea and supper. However, there are $26.2 \%$ of the participants never consume morning tea and afternoon tea. There is significant association between consumption of dinner and supper with BMI $(\mathrm{P}<0.05)$. 


\begin{tabular}{|c|c|c|c|c|c|c|c|}
\hline \multicolumn{2}{|c|}{ Q: Questions } & UW & NW & OW & OB & Total (n/\%) & $p$-value \\
\hline \multirow{5}{*}{ 1) } & How often do you skip meal? & & & & & & \\
\hline & a. Always & $1(0.8)$ & $0(0.0)$ & $1(0.8)$ & $1(0.8)$ & $3(2.4)$ & 0.279 \\
\hline & b. Frequently & $1(0.8)$ & $9(7.1)$ & $5(4.0)$ & $2(1.6)$ & $17(13.5)$ & \\
\hline & c. Sometimes & $9(7.1)$ & $39(31.0)$ & $21(16.7)$ & $6(4.8)$ & $75(59.5)$ & \\
\hline & d. Never & $3(2.4)$ & 20(15.9) & $5(4.0)$ & $3(2.4)$ & $31(24.6)$ & \\
\hline \multirow{4}{*}{ 2) } & Which is more frequently skipped meal? & & & & & & \\
\hline & a. Breakfast & $10(7.9)$ & $49(38.9)$ & $23(18.3)$ & $8(6.3)$ & $90(71.4)$ & 0.859 \\
\hline & b. Lunch & $1(0.8)$ & $7(5.6)$ & $6(4.8)$ & $2(1.6)$ & $16(12.7)$ & \\
\hline & c. Dinner & $3(2.4)$ & $12(9.5)$ & $3(2.4)$ & $2(1.6)$ & $20(15.9)$ & \\
\hline \multirow[t]{5}{*}{ 3) } & Indicate the reasons for skipping meal & & & & & & \\
\hline & a. Time management & $5(4.0)$ & $34(27.0)$ & $16(12.7)$ & $3(2.4)$ & $58(46.0)$ & 0.703 \\
\hline & b. School/Reading & $2(1.6)$ & $15(11.9)$ & $6(4.8)$ & $5(4.0)$ & $28(22.2)$ & \\
\hline & c. Sleeping & $5(4.0)$ & $10(7.9)$ & $7(5.6)$ & $0(0.0)$ & $22(17.5)$ & \\
\hline & d. To reduce weight/Others & $2(1.6)$ & $9(7.1)$ & $3(2.4)$ & $4(3.2)$ & $18(14.3)$ & \\
\hline \multirow[t]{3}{*}{ 4) } & $\begin{array}{l}\text { When do you skip meal, do you take snacks } \\
\text { instead? }\end{array}$ & & & & & & \\
\hline & a. Yes & 10(7.9) & $57(45.2)$ & $18(14.3)$ & $7(5.6)$ & $92(73.0)$ & $* 0.003$ \\
\hline & b. No & $4(3.2)$ & $11(8.7)$ & $14(11.1)$ & $5(4.0)$ & $34(27.0)$ & \\
\hline
\end{tabular}

Pearson Chi-square analysis ( $2 \times 2$ table), $p$-value less than 0.05 is considered significant.

*significantly at $p<0.05$

Meal skipping of the participants and its association with BMI.

Table 4 showed $59.5 \%$ of participants skip at least one meal daily. There are $24.6 \%$ of the participants that are never skipped any of the meal. The most frequently skipped meal is breakfast $(71.4 \%)$ and the lunch was the least $(12.1 \%)$. Most of the reasons for the meal skipping were due to time management. Majority of the students taking snacks when skipped

their meal (73\%). There is significant association between taking snacks when skipped meal and BMI $(p<0.05)$.

\section{Eating out and eating companion}

There is $14.3 \%$ of the participants eat at hawker centers, coffee shops or other food stall daily and majority of the participants $(28.6 \%)$ eat at the outside of their hostel/home only for two to three days per week (Table 5). $37.3 \%$ of the participants reported that they eat at western fast food restaurants only once per month and one to three times per month. Majority of the participants prefer to take their meal with friends $(59.5 \%)$ and $19.8 \%$ of the participants having their meal with family and alone respectively. For vegetables consumptions, only $30.2 \%$ of the participants consume vegetables every day. Only $8.7 \%$ of the participants take fruit every day and $55.6 \%$ of them reported consumption of fruits sometimes. There is none of the participants consume carbonated drinks always. Most of the participants reported that they consume carbonated drinks sometimes (52.4\%) and $44.4 \%$ of the participants never consume carbonated drinks. 
Table 5 Eating out and eating companion of the participants and its association with BMI

Q: Questions

UW NW OW

Total
$(\mathbf{n} / \%)$

1) How often do you consume vegetables?
a. Everyday
b. Frequently
$\begin{array}{llll}1(0.8) & 24(19.0) & 10(7.9) & 3(2.4)\end{array}$
$38(30.2)$
c. Sometimes
$\begin{array}{lllll}4(3.2) & 20(15.9) & 13(10.3) & 4(3.2) & 41(32.5)\end{array}$
$\begin{array}{lllll}9(7.1) & 24(19.0) & 9(7.1) & 5(4.0) & 47(37.3)\end{array}$
2) How often do you take fruit?
a. Everyday
b. Frequently
c. Sometimes
d. Twice per week
$1(0.8)$
$11(8.7)$
$6(4.8)$
$3(2.4)$
$2(1.6)$
$11(8.7)$
$4(3.2)$
$32(25.4)$
19(15.1) 8(6.3)
$6(4.8)$
$70(55.6)$
$\begin{array}{lllll}2(1.6) & 8(6.3) & 3(2.4) & 0(0.0) & 13(10.3)\end{array}$

0.931

3) How often do you take carbonated drinks?
a. Always
b. Frequently
c. Sometimes
d. Never

$0(0.0)$

$9(7.1)$

$3(2.4)$

$0(0.0)$

$1(0.8)$

$5(4.0)$

$4(3.2)$

$66(52.4)$

$5(4.0)$

$34(27.0)$

$11(8.7)$

$6(4.8)$

$56(44.4)$

4) How frequent do you eat at hawker centres, coffee shops or other food stalls?

\begin{tabular}{|c|c|c|c|c|c|c|}
\hline a. & Everyday & $0(0.0)$ & $14(11.1)$ & $3(2.4)$ & $1(0.8)$ & $18(14.3)$ \\
\hline b. & 4 to 6 days per week & $4(3.2)$ & $7(5.6)$ & $5(4.0)$ & $0(0.0)$ & $16(12.7)$ \\
\hline c. & 2 to 3 days per week & $5(4.0)$ & $17(13.5)$ & $10(7.9)$ & $4(3.2)$ & $36(28.6)$ \\
\hline d. & Once a month & $2(1.6)$ & $13(10.3)$ & $4(3.2)$ & $6(4.8)$ & $25(19.8)$ \\
\hline e. & 1 to 3 times per month & $2(1.6)$ & $15(11.9)$ & $7(5.6)$ & $1(0.8)$ & $25(19.8)$ \\
\hline f. & Never & $1(0.8)$ & $2(1.6)$ & $3(2.4)$ & $0(0.0)$ & $6(4.8)$ \\
\hline
\end{tabular}

5) How frequent do you eat at western fast food restaurants?

a. Everyday

b. $\quad 4$ to 6 days per week

c. $\quad 2$ to 3 days per week

d. Once a month

e. 1 to 3 times per month

f. Never $1(0.8) \quad 2(1.6)$ $3(2.4)$

$\begin{array}{lcccc}0(0.0) & 2(1.6) & 0(0.0) & 0(0.0) & 2(1.6) \\ 0(0.0) & 2(1.6) & 3(2.4) & 0(0.0) & 5(4.0) \\ 4(3.2) & 4(3.2) & 4(3.2) & 0(0.0) & 12(9.5) \\ 5(4.0) & 20(15.9) & 15(11.9) & 7(5.6) & 47(37.3) \\ 3(2.4) & 30(23.8) & 9(7.1) & 5(4.0) & 47(37.3) \\ 2(1.6) & 10(7.9) & 1(0.8) & 0(0.0) & 13(10.3)\end{array}$

0.542 western fast food restaurants?
a. Everyday
b. $\quad 4$ to 6 days per week
c. $\quad 2$ to 3 days per week
d. Once a month
e. 1 to 3 times per month
f. Never

7) Who eat with you normally?
a. My family members
b. My friends
c. Alone
d. Other

h

$\begin{array}{lccccc}0(0.0) & 2(1.6) & 0(0.0) & 0(0.0) & 2(1.6) & 0.504 \\ 0(0.0) & 3(2.4) & 2(1.6) & 0(0.0) & 5(4.0) & \\ 5(4.0) & 5(4.0) & 4(3.2) & 0(0.0) & 14(11.1) & \\ 3(2.4) & 20(15.9) & 11(8.7) & 6(4.8) & 40(31.7) & \\ 5(4.0) & 30(23.8) & 14(11.1) & 5(4.0) & 54(42.9) & \\ 1(0.8) & 8(6.3) & 1(0.8) & 1(0.8) & 11(8.7) & \\ & & & & & \\ 4(3.2) & 14(11.1) & 3(2.4) & 4(3.2) & 25(19.8) & 0.650 \\ 7(5.6) & 43(34.1) & 20(15.9) & 5(4.0) & 75(59.5) & \\ 3(2.4) & 11(8.7) & 8(6.3) & 3(2.4) & 25(19.8) & \\ 0(0.0) & 0(0.0) & 1(0.8) & 0(0.0) & 1(0.8) & \end{array}$

Pearson Chi-square analysis ( $2 \times 2$ table), $p$-value less than 0.05 is considered significant.

*significantly at $p<0.05$

\section{Physical activity of the participants}

The mean of time engaged with vigorous intensity activity for overweight participants is the highest which is 29.06 minutes/week, while the least is obesity participants which is 15.83 minutes per week (Table 6). The underweight participants have the longest time engaged with moderate intensity activity which is
42.85 minutes per week and obesity have the shortest time engage with moderate intensity activity which is 16.25 minutes per week. Normal weight participants have the longest time for walking in a week which is 65.49 minutes per week and those that have the least time walking is obesity participants. Normal weight participants also have the longest sitting time which is 
6.5 hours per week compared to obesity (6.3 hours per week). Majority of the participants $(42.9 \%)$ have moderate level of physical activity, followed by $38.1 \%$ of

Table 6 Intensity of physical activity of the participants and its association with BMI

\begin{tabular}{lccccccccc}
\hline \multirow{2}{*}{ Q: Questions } & \multicolumn{2}{c}{ UW } & \multicolumn{2}{c}{ NW } & \multicolumn{2}{c}{ OW } & \multicolumn{2}{c}{ OB } & \multicolumn{1}{c}{$\boldsymbol{p}$-value } \\
\cline { 2 - 11 } & Mean & SD & Mean & SD & Mean & SD & Mean & SD & \\
\hline $\begin{array}{l}\text { Vigorous intensity } \\
\text { (min/week) }\end{array}$ & 21.43 & 56.956 & 27.06 & 56.577 & 29.06 & 43.504 & 15.83 & 21.088 & 0.563 \\
\hline $\begin{array}{l}\text { Moderate intensity } \\
\text { (min/week) }\end{array}$ & 42.86 & 54.832 & 34.49 & 40.905 & 35.00 & 40.897 & 16.25 & 19.671 & 0.573 \\
\hline Walking (min/week) & 59.93 & 89.838 & 65.69 & 116.416 & 40.94 & 57.325 & 27.08 & 30.560 & 0.894 \\
\hline Sitting (hours/week) & 5.79 & 1.929 & 6.50 & 3.560 & 6.44 & 2.526 & 6.33 & 1.775 & 0.917 \\
\hline
\end{tabular}

Kruskal Wallis analysis, $p$-value less than 0.05 is considered has significant association.

*significantly at $p<0.05$

Table 7 Physical activity level of the participants and its association with BMI

\begin{tabular}{lcccccc}
\hline \multicolumn{1}{c}{ Physical activity level } & UW & NW & OW & OB & Total (n/\%) & $\boldsymbol{p}$-value \\
\hline Low & $7(5.6)$ & $23(18.3)$ & $11(8.7)$ & $7(5.6)$ & $48(38.1)$ & 0.526 \\
Moderate & $5(4.0)$ & $29(23.0)$ & $15(11.9)$ & $5(4.0)$ & $54(42.9)$ & \\
\cline { 1 - 4 } High & $2(1.6)$ & $16(12.7)$ & $6(4.8)$ & $0(0.0)$ & $24(19.0)$ & \\
\hline
\end{tabular}

Pearson Chi-square analysis ( $3 \times 2$ table), $p$-value less than 0.05 is considered significant.

*significantly at $p<0.05$

\section{Discussion}

Prevalence of obesity and overweight. The overall prevalence of overweight/ obesity was found to be $34.9 \%$ in Dietetics students of UniSZA in the present study. A similar prevalence was reported among medical students of Karachi which is $33.2 \%$ of the students are obesity/overweight (Asghar et al., 2019). A study conducted among medical students in Government Medical College Kottayam, Kerala also reported similar prevalence of overweight and obesity which is $30.6 \%$ (Thomas \& Geethadevi, 2020). A study among clinical students in Malaysian medical school by (Nem-Yun Boo, 2010) also demonstrated similar prevalence of overweight/obesity which is $30.1 \%$. This finding, however, was inconsistent with a study conducted by (Abdul et al., 2015) showing that overweight and obese were (13.6\%). A research conducted by University of Damman, Kingdom of Saudi Arabia also reported different findings, which is the prevalence of obesity and overweight is $17.6 \%$ (Majeed, 2015). Overall, the subject studied had mostly normal body weight that is consistent with a related study by (Purohit et al., 2015) that showing normal BMI in $56.5 \%$ subjects attending the medical school in India. Similarly, a study of medical students at a medical faculty in a Sudan showed that $66.7 \%$ had normal BMI while $22 \%$ were obese and overweight (Al-haj et al., 2015).

There is no significant association between gender and BMI. A research among university students in Malaysia that showed different results which is there was a significance association between gender and BMI among university students $(p=0.001)$ (Abdul et al., 2015). Studies by (Peltzer \& Pengpid, 2017) among ASEAN university reported there is significant association between gender and BMI. Other than that, a study among medical students by (Thomas \& Geethadevi, 2020) have also demonstrated significant association between gender and BMI. This insignificant result in our sample may be due to limited number of males, who are only seven. 
There is no significant association between living arrangement and BMI, either. Such results were incompatible with a study showing central obesity was associated with living away from parents or guardians on their own or on campus residence (Pengpid \& Peltzer, 2014). Another study by (Pengpid \& Peltzer, 2015) also reported significant association between living arrangement and BMI.

Most of the participants (59.5\%) stated in the current study that they skipped meal sometimes ( $<4$ days per week). The participants stated that most of the factors were due to time management, schools/reading and oversleeping. Certain research also showed similar result which is the key reasons for missing meal due to oversleeping, time management and school schedules (Abubakar et al., 2016) (Goon et al., 2014). The presented study indicate that breakfast is the most frequently missed meal, consistent with other related studies (Hassan et al., 2015) (Asghar et al., 2019) (Musaiger et al., 2015). $27 \%$ of the students had daily breakfast according to our finding and this figure was lower compared to Malaysian medical school in which $43.9 \%$ had daily breakfast (Ganasegeran et al, 2012). A research found that breakfast skipping is a influential promoters of obesity (Hingorjo et al., 2009).

In the current study, on the other hand, majority of the students consumed dinner every day. This might be because the students were hungry as a result of skipping breakfast or lunch. It has been shown that hunger ratings and intake of lunch were found to be significantly increased after skipping breakfast (Levitsky \& Pacanowski, 2013). A research by (Hingorjo et al., 2009) indicated that one of the reason skipping breakfast can raise the risk of obesity, is because of an overall increase in the amount of food eaten by those who skipped breakfast due to hunger, during the day, can contributing to their weight gain.
In this study $73 \%$ of the students consumed snacks when skipped meal and it was significantly associated $(P<0.05)$ with BMI. These results are consistent with other studies which is also indicate significant association between overweight/obesity and snack intake (Majeed, 2015) (Esra Gunes et al., 2012). Some other research also revealed an inverse association between regular frequency of eating and BMI, indicating that increased frequency of both meals and snacks leads to avoidance of obesity (AlRethaiaa et al., 2010).

About $15.1 \%$ of dietetics students ate fast food more than 3 days per week, and no significant association was found between fast food intake and BMI. This proportion is lower than that reported among health sciences students in Bahrain (23\%) (Musaiger et al., 2015). Although our study showed no significant association between fast food consumption and BMI, a study among Kuwaiti female students at university (El-Ghazali S et al, 2010) and medical students Shah et al. (2014) stated that regular fast food consumption was found to be associated with excess body weight.

Fast foods are poor in micronutrients, low in fiber, high energy density, high in glycemic load and large portion size with sugar (Shah T et al., 2014) and could be more energetic than the daily energy requirements (Dumanovsky et al., 2011). In addition, the average energy density of an entire menu in fast food restaurant is approximately more than twice the energy density of a healthy menu (Azadbakht, 2008).

Data from the Western regions (Stea, 2014) (Santaliestra-Pasias et al, 2014) and Arab countries (Al-hazzaa et al., 2011)(Hamrani et al, 2015) showed that adolescents and young people have poor dietary habits, such as the tendency to skip breakfast and have low intakes of fruit, vegetables, milk and fish, and a high intake of sugar-sweetened beverages, fast foods and sweets, and they also skipped 
breakfast. In our report, $37.3 \%$ and $55.4 \%$ of the participants consume vegetables and fruits respectively less than four times per week. However, it does not significantly associate with BMI. This findings in line with a study conducted by (Al-Rethaiaa et al., 2010). Such results are also consistent with studies conducted by (Al-Rethaiaa et al., 2010) and (Esra Gunes et al., 2012) that showed insignificant association between consumption of fruits and vegetables and BMI.

In the current study, $38.2 \%$ of the participants has low physical activity level but there was no significant association between physical activity level and BMI. This result consistent with studies performed by (Pengpid \& Peltzer, 2014) (Thomas \& Geethadevi, 2020) which is there were also did not find that physical inactivity was associated with overweight/obesity. Harikrishnan and Kumar (2018) had found that low levels of physical activity was associated with high prevalence of obesity in a communitybased study done in adolescents in Chennai. A research conducted among students from Medical University of Silesia in Poland also demonstrated that the main reason for not performing physical activity is lack of time and energy (Likus et al., 2013). A lack of time and a preference for other recreation during leisure time has been shown to be the most common explanation for not performing physical exercise (Al-haj et al., 2015) (Łaszek M et al, 2011).

In a nutshell, adverse dietary habits noted were irregularly eating breakfast, consumption of fast food and an insufficient intake of fruit and vegetables. There is therefore a need for pro-healthy education of dietetics students and those also studying related subjects. It is necessary to increase the awareness of appropriate nutrition and levels of physical activity in students taking medically orientated subjects who in the future will be responsible for promoting public health.

\section{Conclusion}

In the young adults populations the incidence of pre-obesity and obesity is significantly increasing. At this pace, complications linked to obesity will form the major chunk of medical illnesses in the near future. Obesity not only decreases lifespan but also reduce the quality of life. Strategies are required to nip this dilemma in the bud, particularly among healthcare personnel who must practice and support healthier lifestyles themselves.

This study had several limitations. The investigation was carried out with dietetics students from one university only, and may not be the representative of dietetics students from other universities. University students are not representative of young adults in general, and the obesity prevalence and its associated factors may be different in other sectors of the population. It is as cross-sectional study, which does not infer causal relationships and provided only a snapshot of current status, further longitudinal studies are needed. We assessed only the frequency of eating fast food without accounting for the portions size, this can give more information about the fast food consumption. The outcome of this study relied on self-report, thus the extent to which participants were inclined to provide socially desirable responses is not fully known.

Despite all the limitations in this study as it used validated questionnaire to assess socio-demographic data, eating behavior as well as physical activity level of the participants. Other than that, the participants in this study also aware with their current weight and height as well as their BMI so that they can take any precaution action to achieve and maintain their weight in healthy normal range.

In conclusion, awareness among the general population about obesity needs to be created, particularly targeting our young adults, in whom the weight gain cycle is in its early stages and would be more easily reversible. Modification of life 
style is essential to develop healthy lifestyle habits earlier. Implementation of initiatives aimed at raising physical activity and promoting healthy diets among students should be emphasized, thereby reducing their future risk of chronic diseases.

\section{References}

Abubakar, H., Razif Bin Shahril, M., Syed, S., \& Wafa, S. (2016). Weight Status, Dietary Intake and Eating Behaviour of Nigerian Postgraduate Students in UniSZA, Malaysia. In Malaysian Journal of Public Health Medicine 16 (3).

Al-hazzaa, H. M., Abahussain, N. A., Alsobayel, H. I., Qahwaji, D. M., \& Musaiger, A. O. (2011). Physical activity, sedentary behaviors and dietary habits among Saudi adolescents relative to age, gender and region. International Journal of Behavioral Nutrition and Physical Activity, 8(1), 140..

Al-Rethaiaa, A. S., Fahmy, A.-E. A., Naseem, †, \& Al-Shwaiyat, M. (2010). Obesity and eating habits among college students in Saudi Arabia: a cross sectional study. 9(39).

Asghar, A., Shah, A. M., Hussain, A. A., Tahir, A., \& Asghar, H. (2019). Frequency of Pre-obesity and Obesity in Medical Students of Karachi and the Predisposing Lifestyle Habits. 11(1), 1-8.

El-Ghazali S, Ibrahim JM, Kandari BM, I. N. (2010). The relationship between lifestyle and body mass index among university students in Kuwait. Egyptian J Comm Med, 28, 69-76.

El-Kassas G, Z. F. (2016). Exploration of the dietary and lifestyle behaviors and weight status and their self-perceptions among health sciences university students in North Lebanon. BioMed Res Int, 1-14.

Esra Gunes, F., Bekiroglu, N., Imeryuz, N., \& Agirbasli, M. (2012). Relation between Eating Habits and a High Body Mass Index among Freshman Students: A Cross-Sectional Study. Journal of the American College of Nutrition, 31(3), 1-8.

Gan, W. Y., Mohd Nasir, M. T., Zalilah, M. S., \& Hazizi, A. S. (2011). Differences in eating behaviours, dietary intake and body weight status between male and female Malaysian university students. Malaysian Journal of Nutrition, 17(2), 213-228.

Ganasegeran K, Al-Dubail S, Qureshi AM, Al-abed AA, RizalAM, A. (2012). Social and psychological factors affecting eating habits among university students in a Malaysian medical school: a cross-sectional study. Nutri $\mathrm{J}, 11,48$.

Giovannini, M., Agostoni, C. and Shamir, R. (2010). Symposium overview: Do we all eat breakfast and is it important? Critical Reviews in Food Science and Nutrition, 50(2), 97-99.

Goon, S., Bipasha, M. S., \& Islam, S. (2014). Fast food consumption and obesity risk among university students of Bangladesh. European Journal of Preventive Medicine, 2(6), 99-104.

Gow RW, Trace SE, M. S. (2010). Preventing weight gain in first year college students: an online Intervention to prevent the freshman fifteen. Eat Behav, 11, 33-39.

Hamrani A, Mehdad S, El-Kari K, ElHamdouchi I, El-Menchawy I, et al. (2015). Physical activity, and dietary habits among Moroccan adolescents. Public Health Nutr, 18, 1793-1800.

Hasamnis, A., Patil, S., Tun, Z. M., \& Ruslan, N. A. binti. (2018). Nutrition and Exercise Habits Amongst Medical Students in a Private University in Malaysia. 285-292.

Hingorjo, M. R., Syed, S., \& Qureshi, M. A. (2009). Overweight and obesity in students of a Dental College of Karachi: Lifestyle influence and 
measurement by an appropriate anthropometric index. Journal of the Pakistan Medical Association, 59(8), 528-532.

Januszyk, K., Liu, Q., \& Lima, C. D. (2011). Activities of human RRP6 and structure of the human RRP6 catalytic domain. Educational and Psychological Measurement, 17(8), 1566-1577.

Łaszek M., Nowacka E., Gawron- Skarbek A., S. F. (2011). Negative behavior patterns of students. Part II. Physical activity and eating habits. Probl Hig Epidemiol, 92(3), 461-465.

Levitsky, D. a, \& Pacanowski, C. R. (2013). Effect of skipping breakfast on subsequent energy intake. Physiology \& Behavior, 119, 9-16.

Likus, W., Milka, D., Bajor, G., Jachaczłopata, M., \& Dorzak, B. (2013). Dietray Habits and Physical Activity in Students from The Medical University of Silesia in Poland. National Institute of Public Health, 64(4), 317-324.

Mahfouz, M. S., Makeen, A. M., Akour, A. Y., Madkhly, T. M., Hakami, H. M., Shaabi, W. M., Ageeli, A. F., Khawaj, F. A., Najmi, K. A., Hakami, S. Y., \& Al-Ali, M. A. (2016). Nutritional habits and weight status among Jazan university students: Eating patterns and healthy lifestyle assessment. Epidemiology Biostatistics and Public Health, 13(2), 1-7.

Mahmoud, M. H., \& Taha, A. S. (2017). The Association between Eating Habits and Body Mass Index among Nursing Students. IOSR Journal of Nursing and Health Science, 06(03), 14-26.

Majeed, F. (2015a). Association of BMI with diet and physical activity of female medical students at the University of Dammam, Kingdom of Saudi Arabia. Journal of Taibah University Medical Sciences, 10(2), 188-196.

Mikolajczyk R, E. A. W. \& M. A. (2009). Food consumption frequency and perceived stress and depressive symptoms among students in three European countries. Nutr J, 8(1), 31.

Moy FM, Johari S, Ismail Y, Mahad R, T. F. \& W. I. W. (2009). (2009). Breakfast skipping and its associated factors among undergraduates in a public university in Kuala Lumpur. Mal J Nutr, 15(2), 165-174.

Musaiger, A. O., Awadhalla, M. S., Almannai, M., \& Alsawad, M. (2015). Dietary habits and sedentary behaviors among health science university students in Bahrain.

Musiager AO, Bader Z, Al-Roomi K, D. R. (2011). Dietary and lifestyle habits amongst adolescents in Bahrain. Food Nutr Res, 55, 7122.

Nem-Yun Boo. (2010). The prevalence of obesity among clinical students in a Malaysian medical school. Singapore Med J, 51(2), 126.

Peltzer, K., \& Pengpid, S. (2017). The Association of Dietary Behaviors and Physical Activity Levels with General and Central Obesity among ASEAN University Students. AIMS Public Health, 4(3), 301-303.

Pendergast, F. J., Livingstone, K. M., Worsley, A., \& Mcnaughton, S. A. (2016). Correlates of meal skipping in young adults: a systematic review. International Journal of Behavioral Nutrition and Physical Activity, 13, 125.

Pengpid, S., \& Peltzer, K. (2014). Prevalence of overweight/obesity and central obesity and its associated factors among a sample of university students in India. Obesity Research and Clinical Practice, 8(6), e558e570.

Pengpid, S., \& Peltzer, K. (2015). Prevalence of overweight and underweight and its associated factors among male and female university students in Thailand. HOMO- Journal of Comparative Human Biology, 66(2), 176-186. 
Perk J., De Backer G., Gohlke H., Graham I., Reiner Z., Verschuren WM., Albus C., Benlian P., Boysen G., Cifkova R., Deaton C., E. S. et al. (2012). European guidelines on cardiovascular disease prevention in clinical practice (version 2012): the fifth joint task force of the European society of cardiology and other societies on cardiovascular disease prevention in clinical practice (constituted by r. Int J Behav Med, 19(4), 403-488.

Purohit, G., Shah, T., \& Jm, H. (2015). Prevalence of Obesity in Medical students and its correlation with cardiovascular risk factors: Emergency Alarm for Today? 13(4).

Rampal L, Rampal S, Khor GL, et al. (2007). A national study on the prevalence of obesity among 16,127 Malaysians. Asia Pac J Clin Nutr, 16(6), 561.

Rautela YS, Reddy BV, Singh AK, G. A. (2018). The prevalence of obesity among adult population and its association with food outlet density in a hilly area of Uttarakhand. J Family Med Prim Care, 7, 809-814.

Shah T, Purohit G, Nair SP, Patel B, Rawal $Y$, S. R. (2014). Assessment of obesity, overweight and its association with the fast food consumption in medical students. J Clin Diagn Res, 8(5), CC05-7.

Thomas, E., \& Geethadevi, M. (2020). Prevalence and determinants of overweight and obesity among medical students. National Journal of Physiology,Pharmacy and Pharmacology, 10(01), 42-48.

World Health Organization. 2013. Global action plan for the prevention and control of non-communicable disease 2013-2020. Geneva, Switzerland. (2013). 2013-2020.

Wy, G., Nasir Mt, M., \& As, H. (2011). Differences in Eating Behaviors, Dietary Intake and Body Weight Status between Male and Female Malaysian University Students. In Mal J Nutr (Vol. 17, Issue 2). 